\title{
INDEXAÇÃO DE DOCUMENTOS NO CONTEXTO DAS OUVIDORIAS
}

\author{
Maria de Fátima Azevedo Neves ${ }^{1}$
}

\begin{abstract}
Resumo
O presente artigo aborda a preocupação necessária no momento de identificar o conteúdo temático dos documentos no caso das Ouvidorias, referenciando quais serão analisados para extrair termos pertinentes e a necessidade de manter o controle dos termos utilizados, visando a busca e o acesso à informação, tendo em vista a indexação como base para a representação do que trata um documento, por meio da análise documentária que é traduzida em linguagem padronizada. Enfatiza a recuperação da informação e considera o vocabulário controlado uma forma de padronização.
\end{abstract}

Palavras-chave: Indexação. Vocabulário Controlado. Ouvidoria. Recuperação da Informação.

DOI:10.37814/2594-5068.2019v2.p197-206

1 Graduada em Estudos Sociais pela Universidade Federal Rural de Pernambuco (UFRPE) e Biblioteconomia Universidade Federal de Pernambuco (UFPE), pós-graduada em Arquivo pela UFPE e Gestão Ambiental - Faculdade Santa Helena (FSH), certificada em Ouvidoria pela Associação Brasileira de Ouvidores Seccional Pernambuco (ABO/PE), funcionária pública da Agência Estadual de Tecnologia da Informação do Estado de Pernambuco (ATI). Atualmente exerce o cargo de Assistente de Ouvidoria na Secretaria de Administração de Pernambuco. (fatima. azevedo@ati.pe.gov.br) 


\begin{abstract}
It addresses the concern that must be had in identifying the thematic content of the documents in the case of the Ombudsman's Office, referring to the documents to be analyzed in order to extract pertinent terms and the need to keep track of the terms used, in order to search and access the information, considering indexing as the basis for the representation of what a document handles through documentary analysis that is translated into standardized language. Emphasizes information retrieval and considers controlled vocabulary a form of standardization.
\end{abstract}

Keywords: Indexing. Controlled Vocabulary. Ombudsman. Information Retrieval. 


\section{INTRODUÇÃO}

Indexação é um processo de análise documental que tem por finalidade identificar o assunto que o documento trata e representá-lo através de descritores, de modo que permita sua pronta recuperação. Ou seja, representar adequadamente o assunto tratado no documento, levando para o contexto das Ouvidorias a ideia passada pelos manifestantes.

LANCASTER (1993) salienta que a indexação de assuntos eficiente implica uma decisão não somente quanto ao assunto que é tratado num documento, mas também quanto à razão que o reveste de um provável interesse para determinado grupo de usuários.

É de fundamental importância a leitura documentária apurada e criteriosa para identificar e selecionar conceitos expressos em um documento e, posteriormente, representar esses conceitos em termos (palavras-chave) que serão adotados no sistema da Ouvidoria.

Partindo do princípio de que as Ouvidorias lidam com informações e tais informações são armazenadas em um sistema, são levantadas questões relativas ao tratamento, controle, acesso e difusão dos conteúdos que são armazenados no sistema utilizado pelas Ouvidorias. Enxergamos os sistemas usados pelas Ouvidorias como similares a outros sistemas de informação que visam à recuperação da informação, precisando para tanto uniformizar seus dados. Não esquecendo, contudo, de observar as especificidades da documentação recebida, no caso, as manifestações.

$\mathrm{Na}$ Ouvidoria, os documentos lidos são as manifestações recebidas e também aqueles diretamente ligados à instituição que representa, como sua missão, sua estrutura organizacional, seu funcionamento e as competências de suas unidades administrativas. Por exemplo, no caso de um órgão do governo, o responsável pela indexação se concentraria na elaboração de termos que representem os serviços, programas e processos da máquina pública do Estado, considerando que a Ouvidoria recebe as manifestações, analisa, trata e identifica o assunto e direciona para o responsável pela área competente responder e que se utiliza de um sistema para acesso a informações.

Por meio deste estudo será possível não só conhecer a dinâmica das Ouvidorias, ampliar conhecimentos com a assimilação de alguns fundamentos teóricos na área de indexação, contribuir na padronização dos assuntos, como também pensar na questão da gestão da informação no âmbito das Ouvidorias. Sabemos que existem assuntos relacionados à Administração Pública que são comuns entre as Ouvidorias, o que nos leva à uniformização das entradas desses assuntos.

\section{DINÂMICA DA OUVIDORIA}

As Ouvidorias normalmente possuem a dinâmica de acolher, escutar o cidadão, analisar as manifestações e encaminhar via sistema ou de outra forma para o responsável pela área competente responder, receber a resposta, analisar a qualidade da resposta e encaminhar ao manifestante (cidadão/servidor), bem como monitorar, posicionar os pontos fortes e fracos, produzir informações qualificadas e sugerir melhorias (através de relatório), visando atender os reais interesses dos cidadãos que ela representa.

Porém, toda essa dinâmica está pautada num conhecimento prévio da instituição em que a Ou- 
vidoria se insere. Lembrando que o conhecimento aparece quando a informação é bem trabalhada. Ou seja, quando é tratada e entendida.

\section{REVISÃO DA LITERATURA}

A inquietude, a dinâmica e a evolução da sociedade têm provocado mudanças significativas. Dentre as mudanças, destaca-se o aumento da produção informacional, a diversificação e o uso cada vez mais independente do suporte documental. Para que essas informações não se percam e sejam recuperadas, é preciso que passem por um tratamento. Por meio de leitura é possível tratar a informação a partir da análise do documento e de sua representação. A análise, a síntese e a representação do conteúdo de um documento são atividades complexas em um sistema de informação e fundamentais à recuperação. A tecnologia facilita o acesso à informação, mas ela por si só não operacionaliza o processo. O uso da indexação sob o ponto de vista dos sistemas de informação é parte importante porque acondiciona os resultados de uma estratégia de busca.

Então, considerando que: i) o volume de manifestações recebidas nas Ouvidorias tende a aumentar, tendo em vista que a sociedade cada vez mais busca esse canal como meio de ser ouvida e ter seus anseios atendidos; ii) as manifestações são matéria-prima para a gestão pública da unidade que ela representa, no caso, o Estado; e iii) a transparência e a melhoria na qualidade dos serviços prestados ao cidadão são de suma importância. Daí a necessidade de definir termos que devem ser utilizados para representar o conteúdo do documento, identificando o assunto com o objetivo de garantir uniformidade nas entradas de assuntos, focando na qualidade das informações inseridas no Sistema da Ouvidoria, de modo que facilitem sua recuperação. Supondo-se que se deseje saber quantas manifestações no ano de 2016 trataram sobre Informe de Rendimento, o resultado irá refletir o conteúdo indexado da especificidade do vocabulário empregado. Ou seja, se o termo pesquisado fizer parte do vocabulário controlado. Por isso é importante elaborar uma lista de termos autorizados.

A elaboração da lista de termos (vocabulário controlado) não é uma tarefa fácil, pois depende do entendimento do conteúdo do documento sob análise para identificar termos e propiciar sua recuperação.

Sabemos que nem sempre as Ouvidorias recebem um documento (manifestação) de fácil entendimento. É aí que paramos, pensamos, lemos, relemos, fixamos nossos olhos na leitura, nas entrelinhas que o texto nos oferece. Podem ocorrer casos em que as pessoas, por estarem azafamadas ou por qualquer outro motivo, leem, mas não leem com precisão e acabam não sendo felizes no momento de identificar o termo que representa o conteúdo da manifestação recebida, ocasionando muitas vezes o encaminhamento da manifestação para uma área que não tem competência para respondê-la, gerando assim um novo encaminhamento.

Indexar é identificar termos (palavras) que expressem o conteúdo do documento, visando à busca e ao acesso da informação. Daí a necessidade do indexador/Ouvidor verificar por meio da leitura a importância dos conceitos selecionados para fazer parte da lista de termos autorizados.

Vale ressaltar que a indexação é um processo pautado na subjetividade, pois trata da análise, 
interpretação e decisão do que será indexado. Por isso temos a consciência de que não é uma tarefa fácil, mas de suma importância no momento da recuperação da informação. Requer a habilidade do indexador (Ouvidor) de contextualizar, relacionar palavras e decidir quais termos serão escolhidos para indicar o conteúdo dos documentos analisados.

Os termos escolhidos pelo indexador servirão como pontos de acesso, permitindo a recuperação através de uma busca por assunto.

A atividade da indexação por assunto, conforme LANCASTER (1993), compreende duas etapas: a análise conceitual e a tradução. $\mathrm{Na}$ análise conceitual é possível identificar o assunto do documento considerando as necessidades dos usuários. Na tradução é possível converter os assuntos identificados em um conjunto de termos de indexação.

No processo de indexação convém mencionar dois elementos importantes que interferem na escolha dos conceitos: a exaustividade e a especificidade. Com relação à exaustividade, é fundamental que o indexador tenha conhecimento no momento da leitura de quantos descritores poderá extrair do texto. No caso da especificidade, será possível nortear o indexador para tornar o assunto de que trata o documento o mais específico possível. O uso da especificidade garante maior precisão na recuperação da informação.

Vocabulário controlado é uma lista de termos (palavras) disposta em ordem alfabética que serve de suporte no momento da indexação, seguindo critérios que objetivam a padronização. $O$ vocabulário controlado inclui em geral uma forma e estrutura semântica. Essa estrutura destina-se a controlar sinônimos e diferenciar homógrafos. Ainda segundo LANCASTER (1993), um vocabulário controlado é essencialmente uma lista de termos autorizados.

A recuperação da informação está atrelada a duas áreas do conhecimento: a Ciência da Computação, que se preocupa com os sistemas de recuperação em si, sua construção e funcionamento, e a Ciência da Informação, que foca a indexação como a base para a representação do que trata um documento.

\section{DICAS PARA ELABORAÇÃO DE VOCABULÁRIO CONTROLADO}

Apresentamos algumas dicas para a construção de um vocabulário controlado que possibilite a busca e recuperação das informações inseridas no Sistema da Ouvidoria.

Na elaboração da Lista de Termos Autorizados, podemos estabelecer alguns critérios, a saber:

- Poderão ser utilizadas uma ou mais palavras como descritor, no entanto, o ideal será a utilização do menor número possível de palavras.

- Os termos deverão ser apresentados no singular. Os termos no plural somente serão permitidos nos casos onde a compreensão do significado da palavra for prejudicada.

- Em relação aos sinônimos, o critério de escolha será do termo mais utilizado pelo público-alvo (cidadão/servidor).

Exemplo: Informe de Rendimento e Comprovante de Rendimento - escolher um dos termos para fazer parte da lista. 
- Os descritores compostos deverão ser apresentados na ordem natural.

Exemplo: Falsificação de Documento - não usar Documento Falsificado.

- Dar preferência ao termo específico.

- Evitar utilizar as palavras "outro" ou "diverso" como termo que represente o assunto, ou seja, o conteúdo do documento analisado.

- Evitar descrição de uma atividade como assunto.

Exemplo: Recebimento e tabulação das frequências - usar o termo Frequência.

- Uso de sigla. Quando mencionada pela primeira vez, deve-se escrever a forma por extenso, seguida da sigla.

- Dispor a Lista de Termos (assuntos) em ordem alfabética.

À medida que os termos vão sendo escolhidos, devem ser inscritos numa lista de termos autorizados (vocabulário controlado). Lembrando que no caso das Ouvidorias a construção da lista é fruto do conhecimento da missão, estrutura organizacional e funcionamento e competências das unidades administrativas da instituição que a Ouvidoria representa.

\section{MANIFESTAÇÃO: ALGUNS EXEMPLOS}

Com base no estímulo teórico recebido, apresentamos a seguir alguns exemplos de manifestações "hipotéticas", embora se baseiem em fatos existentes de manifestações registradas no Sistema da Rede de Ouvidorias do Estado de Pernambuco. Por questão ética e legal, os dados (nome, matrícula, CPF) são fictícios. Assim, procuramos extrair as palavras ou expressões que representam a análise conceitual e, em seguida, traduzimos cada um desses enunciados para um termo ou termos e escolhemos o termo que mais representa o conteúdo da manifestação em análise.

Como foi mencionado anteriormente, a indexação é um processo pautado na subjetividade. Assim, exige conhecimento prévio do assunto. Nem sempre é uma tarefa fácil, especialmente quando o documento é uma manifestação.

\section{Exemplos:}

Sou ex-servidora da Secretaria de Desenvolvimento e estava em exercício na Secretaria da Infraestrutura como Assistente Administrativa, matrícula 0000, CPF 000.000.00000, e quando fui exonerada em agosto de 2006 não recebi minhas férias proporcionais conforme o art. 108-A da Lei 6.123 (Estatuto do Servidor). No referido momento da exoneração, contava com um ano e oito meses de efetivo exercício, tendo usufruído apenas as férias relativas ao primeiro ano, restando portanto $8 / 12$ avos de férias proporcionais a receber. Recebi somente o adicional de $1 / 3$ das férias, porém a legislação diz que deverá ser paga a proporcionalidade do salário mais o adicional, ou seja, eu deveria ter recebido $8 / 12$ avos do meu salário no dia da exoneração, a título de férias indenizatórias, mais o adicional de 1/3. Aguardo posicionamento da questão. 


\section{Indexação: descritores principais}

- Exoneração

- Férias proporcionais

- Revisão de indenização

- Verba indenizatória

Uruçu Mirim Pernambucana da Gema, servidora da Secretaria de Desenvolvimento, matrícula 0002, relata que passou por um inquérito administrativo, instaurado através da Portaria $n^{\circ} 000$ de 20.01.2000, ficando constatado nos autos que não estava errada. No decorrer do processo, procurou obter informação sobre sua lotação e foi informada de que deveria aguardar o término do inquérito para assumir suas atividades profissionais. Durante todo o processo não recebeu seus vencimentos (inclusive o décimo terceiro salário). Sendo assim, pede que seus vencimentos sejam pagos.

\section{Indexação: descritores principais}

- Inquérito administrativo

- Pagamento de salário

- Processo administrativo

Sou servidora pública e gostaria de saber se tenho direito a licença para acompanhar filha menor grávida, após o parto, tendo em vista que ela está sob meus cuidados e reside comigo, não tendo outra pessoa para acompanhá-la. Se sim, como devo proceder.

\section{Indexação: descritores principais}

- Licença

- Licença interesse particular

Estamos em ano eleitoral, sou servidor público e vou concorrer a cargo eletivo. Sei que, ao funcionário ou servidor, é permitido afastar-se para concorrer a cargo político. Gostaria de saber qual o prazo para afastamento.

\section{Indexação: descritores principais}

- Afastamento. Concorrer cargo eletivo

- Eleição

Peço ao responsável pelo imóvel localizado na Rua Tupi, s/n, onde funciona um órgão público, para cuidar da sua lixeira: organizar o lixo para não invadir a calçada e limpar a lixeira para não exalar mau cheiro, pois a lixeira é muito suja. Lembrem-se de que cada um é responsável pelo lixo que produz. 


\section{Indexação: descritores principais}

- Educação ambiental

- Higiene e limpeza

Ex-servidora de contrato temporário informa que, no mês do término do contrato, descobriu que estava grávida e solicitou estabilidade provisória e licença maternidade ao órgão onde prestava serviço, e seu pedido não foi deferido. O contrato não teve a estabilidade provisória assegurada, e, estando no oitavo mês de gestação, pede posicionamento do caso.

\section{Indexação: descritores principais}

- Contrato temporário

- Direito trabalhista

- Estabilidade gestante

- Estabilidade provisória

Trabalho em uma Secretaria do Estado, em ambiente fechado, mas quero manifestar o absurdo de uma pessoa fumar dentro da sala. Uma sala fechada sem ventilação. Sou bastante alérgica! Não tem cristão que suporte trabalhar em um local tão insalubre!

\section{Indexação: descritores principais}

- Ambiente insalubre

- Insalubridade

- Lei antifumo

Prezados, estou denunciando um funcionário que detém três vínculos, o que é ilegal, sendo dois no Estado e um na Prefeitura do Caçote, nome dele é Tupi Falcão, matrícula da Prefeitura 0001; matrículas no Estado: 00002 e 00003 . Informo que, se alguém tentar protegê-lo das medidas cabíveis, faço a denúncia ao Ministério Público e irei citar o protocolo desta denúncia para que as pessoas sejam punidas também.

\section{Indexação: descritores principais}

- Acumulação de cargo

- Cargo público

- Vínculo empregatício

Cidadã relata que um carro Gol, branco, de placa ABC 1000, do Governo do Estado, fez ultrapassagens perigosas, na contramão e quase bateu em seu veículo na Rua Arara em frente à Churrascaria Braz, bairro da Fé, hoje (05/01), por volta das 10h40. Não soube informar a qual secretaria pertencia o carro. 


\section{Indexação: descritores principais}

- Frota

- Veículo

Boa tarde, meu nome é Airam Maria, sou servidora pública lotada no Hospital Otaviano Serrano, matrícula 2018. No dia 17 de abril do corrente, fiz uma solicitação de redução de carga horária porque tenho um filho especial e até o momento não recebi a resposta da Secretaria. Tenho urgência nessa solicitação, pois a minha gerente depende do documento (horário reduzido) para planejamento da escala de trabalho.

\section{Indexação: descritores principais}

- Carga horária

- Horário especial

- Horário especial de trabalho

- Horário reduzido

\section{CONSIDERAÇÕES}

Pela importância das manifestações recebidas nas Ouvidorias para a gestão pública como instrumentos de participação social e seu aprimoramento pelo uso de um sistema de informação para armazenar os dados, acreditamos que este estudo poderá plantar a ideia da construção de uma Lista de Termos Autorizados (Vocabulário Controlado) a fim de usar o processo da indexação como base para a representação do conteúdo dos documentos, o que vai facilitar o trabalho no momento da definição do assunto, bem como oferecer uniformidade e qualidade às informações inseridas no sistema da Ouvidoria, propiciando dessa forma sua efetiva recuperação. E, para as Ouvidorias que trabalham em rede, teríamos um modelo padrão dos assuntos comuns da Rede de Ouvidoria. Como dito anteriormente, o uso do vocabulário controlado evita que existam várias entradas com termos diferentes para o mesmo assunto.

\section{REFERÊNCIAS}

ALMEIDA, J. A utilização de uma solução de business intelligence como apoio ao trabalho de monitoramento e avaliação das Ouvidorias. Revista Científica da Rede de Ouvidoria do Estado de Pernambuco, Recife, n.1, 2. ed., p. 47-58, 2013.

BELLUZO, R. C. B.; FERES, G. G. (Org.). Competência em informação: de reflexões às lições aprendidas. Disponível em: <http://issuu.com/necfci-unb/docs/competnciaeminformaodere>. Acesso em: 15 abr. 2014.

BRAZ, M. I. Política de indexação em sistemas de recuperação da informação: elementos a estabelecer. Disponível em: <http://www.liber.ufpe.br/enegi/anais/GT1Artigo2.pdf>. Acesso em: 02 abr. 2014.

LANCASTER, F. W. Indexação e resumos: teoria e prática. Tradução Antonio Agenor Briquet de Lemos. Brasília: Briquet de Lemos/Livros, 1993. 347p. 
RUBI, Milena Polsinelli. Os princípios da política de indexação na análise de assuntos para a catalogação: especificidade, exaustividade, revocação, precisão na perspectiva dos catalogadores e usuários. Disponível em: <http:// books.scielo.org/id/wcvbc/pdf/boccato-9788579830150-06.pdf>. Acesso em: 19 set. 2014.

SILVA, A. M. et al. Arquivística: teoria e prática de uma ciência da informação. 2. ed., v. 1. Porto/Portugal: Afrontamento, 2012.

SILVA, Maria dos Remédios da; FUJITA, Mariângela Spotti Lopes. A prática de indexação: análise da evolução teórica e metodológica. Disponível em: http://www.scielo.br/pdf/tinf/v16n2/03.pdf. Acesso em: 09 out. 2015.

SISTEMA DA REDE DE OUVIDORIAS DO ESTADO DE PERNAMBUCO. Disponível em: http://www.sistemadeOuvidoria.pe.gov.br/multiwork/controller.

SOUSA, Brisa Pozzi de. Representação temática da informação documentária e sua contextualização em biblioteca. Revista Brasileira de Biblioteconomia e Documentação, São Paulo, v. 9, n. 2, p. 132-146, jul./dez. 2013. Disponível em: http://rbbd.febab.org.br/rbbd/article/view/249/265. Acesso em: 9 out. 2014. 